Nevşehir Bilim ve Teknoloji Dergisi TARGíd Özel Sayı 179-188 2016

DOI: 10.17100/nevbiltek.210985

URL: http://dx.doi.org/10.17100/nevbiltek.210985

\title{
Bazı Kayısı (Prunus armeniaca L.) Çeşitlerinin Farklı Ekolojilerdeki Fenolojik Özelliklerinin Belirlenmesi
}

\author{
Nihal Acarsoy Bilgin ${ }^{1, *}$, Adalet Misırl ${ }^{1}$ \\ ${ }^{1}$ Ege Üniversitesi, Ziraat Fakültesi, Bahçe Bitkileri Bölümü, İzmir
}

Öz

Fenolojik parametreler bitkilerin, biyolojik gelişme dönemlerine işaret etmekte olup, genotiplerin ekolojiye adaptasyonunun tespiti açısından önemlidir. Bu bağlamda, söz konusu parametreler çeşitlere ve ekolojiye göre farklılık göstermektedir. Kayısı yetiştiriciliğinde, Malatya kurutmalık, İzmir ise sofralık üretim merkezleri arasında yer almaktadır. İki farklı ekolojide yetiştirilen sofralık (Iğdır, Tokaloğlu, Precoce de Tyrinthe) ve kurutmalık (Kabaaşı, Hacıhaliloğlu) kayısı çeşitlerinin fenolojik özelliklerinin tespitini amaçlayan bu çalışmada, 3 yıl süreyle tomurcuk kabarması, pembe tomurcuk, çiçeklenme başlangıcı, tam çiçeklenme, çiçeklenme sonu, yapraklanma ve yaprak dökümüne ilişkin gözlemler yapılmıştır.

Araştırma sonucunda, her iki ekolojide genel olarak, tomurcukların, Mart ayında kabardığı ve yaklaşık İzmir'de 3-15, Malatya'da 335 gün sonra pembe tomurcuk dönemine ulaştı̆̆ı saptanmıştır. Çiçeklenmenin yıllara bağlı İzmir'de 2 hafta, Malatya'da 8 hafta farkl1lık gösterdiği, yıllara ve ekolojilere göre Mart - Nisan aylarında gerçekleştiği ve kısa sürdüğü görülmüştür. İncelenen özelliklerin çeşit, lokasyon ve yıllara bağlı olarak değişim gösterdiği belirlenmiştir.

Anahtar Kelimeler: Kayısı, Ekoloji, Fenolojik Gözlemler

\section{Determination of Phenological Characteristics of Some Apricot (Prunus armeniaca L.) Species in Different Ecology}

\begin{abstract}
Phenological parameters indicate the biological growth period of plants. It is important for the determination of ecological adaptation of genotypes. In this context, these parameters vary depending on varieties and ecology. In Apricot cultivation, Malatya is situated to dried and Izmir is situated to table varieties growing centers. This study was carried out to determine phenological characteristics of table (Iğdır, Tokaloğlu, Precoce de Tyrinthe), and dried (Kabaaşı, Hacıhaliloğlu) apricot cultivars in two different ecology. Buds swell, bud burst, start of blooming, full bloom, end of blooming, foliation and defoliation periods were observed for 3 years.

As a result, in general for both ecology, the buds were swelled in March and approximately 3-15 days in Izmir, 3-35 days in Malatya after it was determined that reached the pink bud period. The blooming was showed differences 2 weeks in Izmir, 8 weeks in Malatya some years, according to year and ecology was observed in March-April and completed in a short duration. It was determined that the observed characteristics were changed depending on the variety, location and year.
\end{abstract}

Keywords: Apricot, Ecology, Phenological Observations

*e-mail: nihalacarsoy@yahoo.com 


\section{Giriş}

Farklı ekolojik koşullara sahip olan Türkiye'de, çok sayıda meyve tür ve çeşidi yetiştirilebilmektedir. Bu meyve türleri arasında hemen hemen her bölgeye büyük oranda adaptasyon göstererek başarılı bir şekilde yetiştirilen ve beğenilerek tüketilen kayısı, ilk sırada yer almaktadır [1 ve 2].

Dünya kayısı üretiminde ve ihracatta önemli bir noktada bulunan Türkiye'de, yetiştiriciliği yapılan kayısının büyük bir bölümü kurutmalık olarak değerlendirilmektedir. Bu bağlamda, Malatya ili özel ekolojik koşulların sağladığı avantajlar sayesinde üretimde ilk sırada yer almaktadır. Ülkemizde özellikle kurutmalık çeşitlerle yapılan üretim ön planda olmasına rağmen, Dünyada üretilen kayısıların önemli bölümü sofralık olarak tüketilmektedir.

Akdeniz Bölgesi’nde yoğun olarak yetiştiriciliği yapılan sofralık çeşitlerin erken dönemde olgunlaşarak ihraç edilebilme şansının yüksek olması nedeniyle bu üretim şeklinin ağırlık kazandığı görülmektedir. Bu bakımdan, Ege Bölgesi’nde özellikle İzmir, önemli kayısı üretim merkezleri arasında yer almaktadır. Son yıllarda, sofralık kayısı yetiştiriciliğinin gelişme gösterdiği, iç ve dış pazar açısından talep gören ve ekonomik değer taşıyan çeşitler ile söz konusu ekolojide çok sayıda yeni bahçelerin tesis edildiği görülmektedir.

Sofralık kayısı yetiştiriciliğinin yoğun olarak yapıldığı ve ülkemizin de dahil olduğu Akdeniz Havzası ülkelerinde geniş alanlarda yayılım gösteren az veya düzensiz ürün veren sofralık çeşitlerin varlığı, üzerinde durulması gereken konulardan biri olarak gündeme gelmektedir. İklimin yetiştiricilik açısından sınırlayıcı bir faktör olması nedeniyle, özellikle günümüzde küresel ısınmanın da etkisiyle ekstrem sıcaklıkların yaşanması bazı kültür bitkilerinin yetiştirilme alanlarını sınırlamaktadır. Bu durum, kayısı çeşitlerinin farklı ekolojik koşullara adaptasyon yeteneğini oldukça kısıtlamakta, verimde belirgin biçimde azalma görülmektedir [3].

Meyve türlerinde, genel olarak, yüksek verim ve kaliteli ürün için, tozlanma ve döllenmenin gerçekleşmesi gerekmektedir. Bu durum, bahçe tesisinde uygun tozlayıcı çeşitlere yer verilmesiyle çözüme kavuşabilir. Bu bağlamda, fenolojik gözlemler ile çiçeklenme zamanı çakışan uygun tozlayıcı çeşitlerin belirlenmesine özen gösterilmelidir.

Meyve ağaçlarında genotiplerin çiçeklenme zamanı kadar süresi de önemlidir. Buna göre, uzun bir çiçeklenme süresi, döllenme olasılığını arttırmaktadır [4]. Erzincan Merkez ve Üzümlü ilçesine bağlı belde ve köylerde yürütülen seleksiyon çalışması sonucunda belirlenen toplam 17 kayısı ile zerdali çeşit ve tiplerinde, tozlanma ve döllenme üzerine etkili olduğu bilinen çiçeklenme süresinin 5 - 17 gün arasında değiştiği belirtilmektedir [5].

Fenolojik parametreler bitkilerin, biyolojik gelişme dönemlerinin bir göstergesi olarak değerlendirilmekte, genotiplerin davranışını belirlemek açısından önem taşımaktadır. Meyve ağaçlarının tam çiçeklenme, meyve olgunluğu ve yaprak dökümü gibi fenolojik evreleri, yıllara ve aynı zamanda ekolojilere bağlı olarak büyük farklılıklar göstermektedir [6-7-8-9]. Bu bağlamda, Malatya ve yöresinde 13 tip ve 4 çeşitte iki yıl süreyle yapılan gözlemlerde, genotipler arasında fenolojik aşamalarda yaklaşık olarak 8 - 10 gün olacak şekilde varyasyon ortaya çıktığı belirlenirken [10], farklı araştırıcılar ise safhalar arasında yaklaşık 2 ay farklılık görülebileceğine dikkat çekmektedirler [11]. 
Kayısıda melezleme 1slah programından elde edilen melez populasyonda Malatya ekolojik koşullarında iki yıllık fenolojik değerlendirmede, tomurcuk kabarması, pembe tomurcuk, çiçeklenme başlangıcı, tam çiçeklenme, çiçeklenme sonu, yapraklanma, yaprak dökümü ve hasat zamanı gibi parametrelerin değiş̧enliği dikkat çekmiştir. Araştırıcılar, çiçeklenme zamanı bakımından genotipler arasında farklılığı vurgulamakla birlikte, yıllar arasında da varyasyon ortaya çıktığını gözlemişlerdir [12].

Kayısı yetiştiriciliğinin yoğun olarak yapıldığı, Malatya yöresinde Battalgazi, Merkez ve Akçadağ gibi farklı ekolojilerde üretimi yapılan Hacıhaliloğlu, Kabaaşı, Hasanbey ve Çataloğlu gibi kurutmalık kayısı çeşitleri ile 2009 yılında yürütülen çalışmada, ekolojik koşulların fenolojik safhaların değişimi üzerine etkisi irdelenmiştir. Battalgazi en düşük, Akçadağ ise en yüksek rakıma sahip ekolojiler olması nedeniyle fenolojik safhaların en erken Battalgazi'de, en geç Akçadağ ilçesinde tespit edildiği gözlenmiştir. $\mathrm{Bu}$ durumun, yükseltiye bağlı olarak sıcaklık değişiminden kaynaklandığı ifade edilmektedir. Ayrıca çiçeklenme, hasat ve meyve gelişim periyodunun rakımdan en fazla etkilenen özellikler olduğu vurgulanmaktadır [13]. Benzer şekilde, 1996 - 1997 periyodunda yine Malatya ilinin yüksek rakımlı yöresinde yürütülen diğer bir araştırmada, vejetasyon periyodunun rakıma bağlı olarak kısaldığı ve Şekerpare çeşidinin 15 Mayıs, Kabaaşı çeşidinin ise 17 Mayıs olmak üzere bu tarihler arasında tam çiçeklenme dönemine ulaştıkları kaydedilmektedir [14]. İran'da 3 faklı ekolojik koşulda; incelenen lokal kayısı çeşitlerinde çiçeklenme zamanı bakımından incelenen lokasyonlar arasında ekolojik koşullara bağlı olarak yaklaşık 10 gün farklılık olduğu tespit edilmiştir [15].

Meyve tür ve çeşitlerinde belirli lokasyonlar için çalışmaların temelini oluşturan fenolojik evrelerin belirlenmesine yönelik çalışmalar gerçekleştirilmektedir. Nitekim söz konusu veriler, ekonomik anlamda yetiştiricilik için genotiplerin ekolojiye adaptasyonunun belirlemesi açısından önem taşımaktadır. Bu bağlamda, iki farklı ekolojik koşullarda yetiştirilen sofralık ve kurutmalık kayısı çeşitlerinin fenolojik özelliklerinin tespitini amaçlayan bu çalışmada, 3 yıl süreyle tomurcuk kabarması, pembe tomurcuk, çiçeklenme başlangıcı, tam çiçeklenme, çiçeklenme sonu, yapraklanma ve yaprak dökümü tarihleri belirlenmiştir.

\section{Materyal ve Metot}

Araştırma, 2009 - 2011 yılları arasında Ege Üniversitesi Ziraat Fakültesi Bahçe Bitkileri Bölümü ve Malatya Meyvecilik Araştırma İstasyonu koleksiyon bahçelerinde yürütülmüştür. İzmir'de deneme bahçesinin koordinatı $38^{\circ} 27^{\prime} 06.52^{\prime \prime} \mathrm{K}$ ve $27^{\circ} 13^{\prime} 23.08^{\prime \prime} \mathrm{D}$, deniz seviyesinden yüksekliği $26 \mathrm{~m}$ iken,

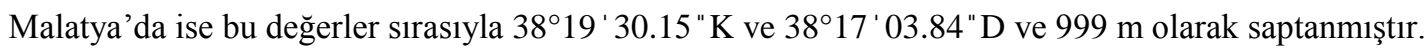

Sofralık olarak değerlendirilen ve İzmir ekolojik koşullarında düzensiz ürün veren Iğdır, Tokaloğlu ve düzenli ürün veren, soğuklama ihtiyacı düşük olan Precoce de Tyrinthe (kontrol) çeşitleri ile soğuklama ihtiyacı yüksek olan kurutmalık Kabaaşı ve Hacıhaliloğlu çeşitlerinin iki farklı ekolojide tomurcuk kabarması, pembe tomurcuk, çiçeklenme başlangıcı, tam çiçeklenme, çiçeklenme sonu, yapraklanma ve yaprak dökümü gibi parametrelere ait tarihler kaydedilmiştir. İzmir lokasyonundaki çeşitler 16, Malatya lokasyonundaki çeşitler ise 37 yaşında olup çöğür anacı üzerine aşılıdır. Denemenin yürütüldüğü yıllara ait Meteoroloji Genel Müdürlüğü’nden temin edilen maksimum, minimum ve ortalama sıcaklık değerleri İzmir ve Malatya için sırasıyla Tablo 1 ve 2'de sunulmuştur. 
Çiçek tomurcuklarının şişkinleşip kabarmaya başladığı tarih, tomurcuk kabarması; taç yapraklarının pembe - beyaz uç gösterdikleri tarih, pembe tomurcuk; çiçek tomurcuklarının ortalama \%510’unun açıldığg tarih, çiçeklenme başlangıcı; \%70-75’inin açıldığı tarih, tam çiçeklenme ve taç yaprakların \%90’inin döküldügü dönem ise çiçeklenme sonu olarak kabul edilmiştir [16-17-18]. Ayrıca ilkbaharda sürgün tomurcuklarının uyanması ile yaprakların görülmeye başladığı ve sonbaharda yaprakların döküldüğü tarih sırasıyla yapraklanma ve yaprak döküm zamanı olarak kaydedilmiştir [16 ve 19].

Tablo 1. İzmir iline ait sıcaklık değerleri (maksimum-minimum-ortalama ${ }^{0} \mathrm{C}$ )

\begin{tabular}{cccccccccc} 
& & $\mathbf{2 0 0 9}$ & & & $\mathbf{2 0 1 0}$ & \multicolumn{3}{c}{$\mathbf{2 0 1 1}$} \\
Ocak & 19.0 & 1.3 & 10.5 & 22.4 & -2.2 & 10.5 & 17.8 & 1.4 & 9.1 \\
Şubat & 20.4 & 2.9 & 10.0 & 23.8 & 0.0 & 12.5 & 19.7 & 2.3 & 10.2 \\
Mart & 24.0 & 2.2 & 11.7 & 22.8 & 3.7 & 13.3 & 22.8 & 0.9 & 12.0 \\
Nisan & 26.2 & 7.4 & 16.0 & 28.7 & 8.4 & 17.4 & 23.4 & 5.2 & 14.5 \\
Mayıs & 31.7 & 11.1 & 21.4 & 35.4 & 11.9 & 21.9 & 30.5 & 9.1 & 20.1 \\
Haziran & 34.9 & 16.7 & 26.2 & 35.9 & 16.7 & 25.6 & 35.4 & 17.6 & 25.4 \\
Temmuz & 38.9 & 21.0 & 29.0 & 37.7 & 20.4 & 28.8 & 37.2 & 20.0 & 28.9 \\
Ağustos & 37.4 & 19.5 & 27.8 & 40.0 & 22.7 & 30.2 & 36.9 & 19.1 & 28.1 \\
Eylül & 33.6 & 14.6 & 23.2 & 32.6 & 17.7 & 25.0 & 34.4 & 18.9 & 25.6 \\
Ekim & 28.7 & 12.4 & 20.8 & 27.5 & 7.8 & 18.8 & 27.4 & 6.5 & 17.2 \\
Kasım & 25.0 & 5.0 & 14.6 & 25.6 & 9.1 & 18.1 & 19.3 & 2.6 & 11.2 \\
Aralık & 20.1 & 4.7 & 13.1 & 24.5 & 0.3 & 13.2 & 20.1 & 0.6 & 10.6 \\
\hline
\end{tabular}

Tablo 2. Malatya iline ait sıcaklık değerleri (maksimum-minimum-ortalama ${ }^{0} \mathrm{C}$ )

\begin{tabular}{llllllllll}
\multicolumn{1}{c}{} & $\mathbf{2 0 0 9}$ & & & $\mathbf{2 0 1 0}$ & & $\mathbf{2 0 1 1}$ & \\
& Max & Min & Ort & Max & Min & Ort & Max & Min & Ort \\
Ocak & 9.0 & -9.2 & 1.0 & 13.5 & -10.2 & 3.0 & 9.8 & -5.2 & 2.6 \\
Şubat & 14.2 & -3.4 & 4.6 & 15.4 & -4.8 & 5.5 & 12.5 & -6.1 & 2.9 \\
Mart & 20.4 & -1.8 & 6.6 & 23.1 & -2.1 & 10.5 & 20.4 & -1.7 & 8.2 \\
Nisan & 21.8 & 3.2 & 12.6 & 26.1 & 4.0 & 13.6 & 23.7 & -0.9 & 12.0 \\
Mayıs & 32.6 & 6.8 & 18.5 & 32.6 & 8.5 & 19.9 & 30.6 & 6.6 & 16.4 \\
Haziran & 36.6 & 14.2 & 25.0 & 35.2 & 12.0 & 23.5 & 35.5 & 12.9 & 23.1 \\
Temmuz & 38.0 & 16.2 & 27.0 & 39.0 & 16.4 & 27.8 & 40.4 & 16.6 & 28.6 \\
Ăgustos & 37.2 & 14.0 & 25.7 & 40.6 & 18.5 & 29.9 & 39.8 & 15.1 & 27.4 \\
Eylül & 34.0 & 6.6 & 20.7 & 36.3 & 14.6 & 25.8 & 33.1 & 13.2 & 22.9 \\
Ekim & 28.0 & 9.2 & 17.9 & 27.3 & 5.6 & 16.0 & 27.6 & 4.5 & 14.9 \\
Kasım & 15.2 & -0.3 & 8.1 & 18.9 & 3.0 & 11.4 & 16.4 & -6.1 & 4.9 \\
Aralık & 12.0 & -2.9 & 5.3 & 17.5 & -2.2 & 4.8 & 9.4 & -4.5 & 1.7 \\
\hline
\end{tabular}

\section{Bulgular}

Fenolojik gözlemlere ilişkin veriler İzmir ve Malatya lokasyonları için sırasıyla Tablo 3 ve 4'te verilmiştir. İncelenen çeşitlerde her iki ekolojide, genel olarak, tomurcukların Mart ayında kabardığı belirlenmiştir. Soğuklama ihtiyacı düşük olan Precoce de Tyrinthe çeşidi bu evreye en erken dönemde ulaşmıştır. Pembe tomurcuk dönemi, ilk aşamadan yaklaşık 3 - 35 gün sonra saptanmış olup. Bu dönemin genel anlamda, 2009 ve 2011 yıllarında Malatya ekolojisinde İzmir'e göre daha geç, 2010 yılında ise daha erken olduğu görülmüştür.

Çiçeklenme başlangıcı, yıllara göre sırasıyla, İzmir'de 25 (Tokaloğlu ve Precoce de Tyrinthe) 28 Mart (Hacıhaliloğlu, Iğdır ve Kabaaşı), 13 (Precoce de Tyrinthe) - 29 Mart (Iğdır) ve 21 (Precoce de Tyrinthe) - 28 Mart (Iğdır) aralığında tespit edilmiştir. Malatya'da ise, 2 (Tokaloğlu ve Precoce de Tyrinthe) - 3 Nisan (Hacıhaliloğlu, Iğdır ve Kabaaşı), 11 (Precoce de Tyrinthe) - 17 Mart (Tokaloğlu) ve 
23 (Precoce de Tyrinthe) - 29 Mart (Iğdır ve Tokaloğlu) olarak belirlenmiştir. Tam çiçeklenme periyodu yıllara göre sırasıyla, İzmir’de 28 (Precoce de Tyrinthe) - 30 Mart (Hacıhaliloğlu, Iğdır ve Kabaaşı), 16 (Precoce de Tyrinthe) - 30 Mart (Iğdır) ve 24 (Precoce de Tyrinthe) - 30 Mart (Iğdır), Malatya'da ise; 3 (Precoce de Tyrinthe) - 7 Nisan (Iğdır, Kabaaşı ve Tokaloğlu), 13 (Precoce de Tyrinthe) - 20 Mart (Tokaloğlu) ve 25 Mart (Precoce de Tyrinthe) - 1 Nisan (Iğdır ve Tokaloğlu) tarihleri arasında kaydedilmiştir.

Çiçeklenme başlangıcı, tam çiçeklenme ve çiçeklenme sonunu kapsayan çiçeklenme periyodu genel olarak değerlendirildiğinde, denemenin ilk yılında İzmir'de Tokaloğlu ve Precoce de Tyrinthe çeşitlerinde 25 Mart, Hacıhaliloğlu, Iğdır ve Kabaaşı çeşitlerinde ise 28 Mart’ta başlayan çiçeklenme periyodu yaklaşık 5 gün devam etmiştir. Bu periyot Precoce de Tyrinthe çeşidinde 30 Mart'ta diğer çeşitlerde de 2 Nisan'da son bulmuştur. Aynı yıl Malatya'da havaların daha serin geçmesi nedeniyle Nisan ayının ilk yarısında çiçeklenme görülmüştür. Buna göre, Tokaloğlu ve Precoce de Tyrinthe çeşitlerinde 2 Nisan, diğer çeşitlerde ise 3 Nisan'da başlayan çiçeklenme periyodu Precoce de Tyrinthe çeşidinde 5 Nisan, diğer çeşitlerde ise 10 Nisan'da son bulmuştur. Denemenin ikinci yılında ise, İzmir'de çiçeklenme başlangıç tarihi 13 - 29 Mart olarak belirlenirken, 22 Mart - 5 Nisan tarihleri arasında çiçeklenmenin sonlandığı tespit edilmiştir. Malatya'da ise, 11 - 17 Mart tarihleri arasında başlayan çiçeklenme periyodu yaklaşık 4 gün devam ederek, 15 - 22 Mart tarihleri arasında sona ermiştir. Denemenin üçüncü yılında, bu periyodun ilk olarak Precoce de Tyrinthe çeşidinde (21 - 26 Mart), son olarak da Iğdır çeşidinde (28 Mart - 3 Nisan) başladığı ve sonlandığı tespit edilmiştir. Malatya'da ise, çiçeklenme 23 (Precoce de Tyrinthe) - 29 Mart (Iğdır) tarihleri arasında başlayıp, 28 Mart (Precoce de Tyrinthe) - 4 Nisan (Tokaloğlu) tarihleri arasında tamamlanmıştır.

Çeşitlerin yapraklanma başlangıcının İzmir ve Malatya ekolojilerinde, 2009 ve 2011 yıllarında Nisan, 2010 yılında ise Mart ayında olduğu tespit edilmiştir. Üç yıllık değerlendirmede, yaprak döküm tarihleri bakımından, ilk yıl çeşitler bazında İzmir ve Malatya koşullarında diğer yıllara göre değişim aralığının daha fazla olduğu görülmüştür. Buna göre, yapraklar İzmir’de, ilk yıl Kasım, diğer yıllarda ise Aralık ayında dökülmüştür.

Tablo 3.Kayısı çeșitlerinde fenolojik gözlemler (İzmir)

\begin{tabular}{|c|c|c|c|c|c|c|c|c|}
\hline Çeșit & Yll & $\begin{array}{l}\text { Tomurcuk } \\
\text { kabarması }\end{array}$ & $\begin{array}{c}\text { Pembe } \\
\text { tomurcuk }\end{array}$ & $\begin{array}{c}\text { Çiçeklenme } \\
\text { bașlangıcı }\end{array}$ & $\begin{array}{c}\text { Tam } \\
\text { çiçeklenme }\end{array}$ & $\begin{array}{c}\text { Çiçeklenme } \\
\text { sonu }\end{array}$ & Yapraklanma & $\begin{array}{r}\text { Yaprak } \\
\text { dökümüi }\end{array}$ \\
\hline \multirow{3}{*}{ Hacıhaliloğlu } & 2009 & 10.03 & 25.03 & 28.03 & 30.03 & 02.04 & 10.04 & 29.11 \\
\hline & 2010 & 05.03 & 15.03 & 19.03 & 21.03 & 27.03 & 30.03 & 27.12 \\
\hline & 2011 & 15.03 & 21.03 & 26.03 & 28.03 & 02.04 & 05.04 & 20.12 \\
\hline \multirow{3}{*}{ Iğdır } & 2009 & 12.03 & 24.03 & 28.03 & 30.03 & 02.04 & 08.04 & 29.11 \\
\hline & 2010 & 15.03 & 26.03 & 29.03 & 30.03 & 05.04 & 10.04 & 27.12 \\
\hline & 2011 & 13.03 & 20.03 & 28.03 & 30.03 & 03.04 & 05.04 & 20.12 \\
\hline \multirow{3}{*}{ Kabaașı } & 2009 & 10.03 & 25.03 & 28.03 & 30.03 & 02.04 & 10.04 & 26.11 \\
\hline & 2010 & 05.03 & 15.03 & 19.03 & 21.03 & 27.03 & 30.03 & 26.12 \\
\hline & 2011 & 12.03 & 15.03 & 25.03 & 27.03 & 29.03 & 01.04 & 20.12 \\
\hline \multirow{3}{*}{ Tokaloğlu } & 2009 & 08.03 & 22.03 & 25.03 & 29.03 & 02.04 & 08.04 & 18.11 \\
\hline & 2010 & 01.03 & 12.03 & 16.03 & 20.03 & 25.03 & 27.03 & 27.12 \\
\hline & 2011 & 14.03 & 20.03 & 24.03 & 27.03 & 30.03 & 02.04 & 25.12 \\
\hline \multirow{3}{*}{$\begin{array}{c}\text { Precoce de } \\
\text { Tyrinthe }\end{array}$} & 2009 & 06.03 & 20.03 & 25.03 & 28.03 & 30.03 & 06.04 & 18.11 \\
\hline & 2010 & 29.02 & 10.03 & 13.03 & 16.03 & 22.03 & 25.03 & 15.12 \\
\hline & 2011 & 09.03 & 18.03 & 21.03 & 24.03 & 26.03 & 28.03 & 25.12 \\
\hline
\end{tabular}


Tablo 4. Kayısı çeşitlerinde fenolojik gözlemler (Malatya)

\begin{tabular}{|c|c|c|c|c|c|c|c|c|}
\hline Çeșit & Yll & $\begin{array}{l}\text { Tomurcuk } \\
\text { kabarması }\end{array}$ & $\begin{array}{l}\text { Pembe } \\
\text { tomurcuk }\end{array}$ & $\begin{array}{l}\text { Çiçeklenme } \\
\text { bașlangıcı }\end{array}$ & $\begin{array}{c}\text { Tam } \\
\text { çiçeklenme }\end{array}$ & $\begin{array}{l}\text { Çiçeklenme } \\
\text { sonu }\end{array}$ & Yapraklanma & $\begin{array}{r}\text { Yaprak } \\
\text { dökümü }\end{array}$ \\
\hline \multirow{3}{*}{ Hacihaliloğlu } & 2009 & 02.03 & 01.04 & 03.04 & 05.04 & 10.04 & 12.04 & 29.11 \\
\hline & 2010 & 06.03 & 11.03 & 12.03 & 14.03 & 16.03 & 19.03 & 15.11 \\
\hline & 2011 & 16.03 & 20.03 & 24.03 & 26.03 & 31.03 & 01.04 & 15.11 \\
\hline \multirow{3}{*}{ Iğdır } & 2009 & 28.03 & 01.04 & 03.04 & 07.04 & 10.04 & 12.04 & 29.11 \\
\hline & 2010 & 08.03 & 13.03 & 14.03 & 16.03 & 17.03 & 20.03 & 15.11 \\
\hline & 2011 & 20.03 & 23.03 & 29.03 & 01.04 & 03.04 & 02.04 & 15.11 \\
\hline \multirow{3}{*}{ Kabaașı } & 2009 & 02.03 & 01.04 & 03.04 & 07.04 & 10.04 & 12.04 & 29.11 \\
\hline & 2010 & 05.03 & 11.03 & 13.03 & 15.03 & 17.03 & 20.03 & 15.11 \\
\hline & 2011 & 20.03 & 23.03 & 28.03 & 30.03 & 03.04 & 01.04 & 10.11 \\
\hline \multirow{3}{*}{ Tokaloğlu } & 2009 & 28.03 & 01.04 & 02.04 & 07.04 & 10.04 & 12.04 & 10.11 \\
\hline & 2010 & 08.03 & 14.03 & 17.03 & 20.03 & 22.03 & 25.03 & 12.11 \\
\hline & 2011 & 23.03 & 27.03 & 29.03 & 01.04 & 04.04 & 01.04 & 10.11 \\
\hline \multirow{3}{*}{$\begin{array}{l}\text { Precoce de } \\
\text { Tyrinthe }\end{array}$} & 2009 & 25.02 & 01.04 & 02.04 & 03.04 & 05.04 & 06.04 & 10.11 \\
\hline & 2010 & 06.03 & 09.03 & 11.03 & 13.03 & 15.03 & 18.03 & 12.11 \\
\hline & 2011 & 10.03 & 18.03 & 23.03 & 25.03 & 28.03 & 28.03 & 10.11 \\
\hline
\end{tabular}

\section{Tartışma ve Sonuç}

Farklı ekolojik koşullarda, meyve tür ve çeşitlerinde, fenolojik verilerin elde edilmesi, yaşam çemberinde periyodik olarak ortaya çıkan olayların belirlenmesi açısından büyük önem taşımaktadır. Bu bağlamda, iki farklı ekolojik koşulda yetiştirilen Iğdır, Tokaloğlu, Precoce de Tyrinthe, Kabaaşı ve Hacıhaliloğlu kayısı çeşitlerinde 3 yıl süreyle yapılan fenolojik gözlemler sonucunda çiçeklenme döneminin yıllara bağlı olarak İzmir'de 2 hafta, Malatya'da 8 hafta kadar farklılık gösterdiği belirlenmiştir. Çiçeklenmenin İzmir lokasyonunda Malatya’ya göre daha stabil olduğu dikkat çekmiştir. $\mathrm{Bu}$ durumun, İzmir ekolojisinde, ekstrem iklim koşullarının ortaya çıkmaması ve ılıman Akdeniz ikliminin etkisinin doğal bir sonucu olabildiği düşünülmektedir. Diğer taraftan, Malatya ekolojisinde çiçeklenme zamanı bakımından ortaya çıkan büyük farklılık, soğuklanma gereksinimlerinin karşılanmasına rağmen çiçeklenme için gerekli ortalama sıcaklık değerlerine $\left(15^{0} \mathrm{C}\right)$ farklı tarihlerde ulaşılabilmesinden kaynaklanmaktadır. İki lokasyondaki duruma benzer şekilde, Romanya'da 11 kayısı çeşidi ile yürütülen çalışmada da ekolojiye bağlı olarak çeşitler arasında farklılığın ortaya çıkabileceği vurgulanmıştır [20]. Fenolojik evrelerin farklı lokasyonlarda yıllara bağlı olarak değişim göstermesi, Malatya [21] ve Van [22] ekolojik koşullarında yetiştirilen farklı kayısı çeşitlerinde elde edilen verilerle de uyum içerisindedir.

İncelenen çeşitlerin deneme süresince farklı zamanda çiçeklenmesi ekolojik koşullar ve iklim koşullarının yıllara göre değişiminin bir sonucu olarak ortaya çıkabilmektedir. Deniz seviyesinden yüksekliği farklı olan İzmir ve Malatya lokasyonlarında, incelenen kayısı çeşitlerinin ikinci lokasyonda daha geç dönemde tam çiçeklenme aşamasına ulaştığı tespit edilmiştir. Bunu destekler biçimde, Malatya'da Battalgazi, Merkez ve Akçadağ gibi farklı ekolojilerde, Hacıhaliloğlu ve Kabaaşı kayısı çeşitlerinde fenolojik safhaların en erken Battalgazi'de, en geç ise Akçadağ ilçesinde başladığı bildirilmektedir [13]. Yine Malatya ilinin yüksek rakımlı yöresinde yetiştirilen kayısı çeşitlerinin çok geç 
dönemde (Mayıs) çiçeklendiğine dikkat çekilmektedir [14]. Ayrıca, İran'da 3 farklı lokasyonda kayısı çeşitlerinin çiçeklenme zamanı bakımından yaklaşık 10 günlük farklılık tespit edilmiştir [15]. Bu bağlamda, araştırma bulgularının diğer araştırma sonuçları ile paralel bir durum sergilediği görülmektedir.

Precoce de Tyrinthe, deneme süresince en erken çiçeklenen çeşittir. Bunu destekler biçimde, bu çeşidin, erkencilik açısından önemli potansiyele sahip Aydın [23], Adana [24-25-26-27] ve İzmir [28] ekolojik koşullarında gelişme performansının iyi ve soğuklama ihtiyacı az olması nedeniyle, söz konusu ekolojilere uyum sağladığı belirtilmektedir.

Üç yıllık verilerin genel değerlendirilmesi sonucunda, çiçeklenme periyodunun yıllara ve ekolojilere göre Mart - Nisan aylarında gerçekleştiği ve kısa sürdüğü görülmüştür. Bu bulgu, farklı kayısı genotipleri için diğer araştırıcılar tarafından da teyit edilmektedir [9]. Hava sıcaklığının yıllara bağlı olarak büyük ölçüde değişim göstermesi, fenolojik aşamaların başlangıcını ve süresini de etkilemektedir. $\mathrm{Bu}$ bağlamda, kayısı genotiplerinin çiçeklenme periyodunun kısa olmasının yıllara bağlı olarak bu dönemdeki sıcaklık artışının doğal bir sonucu olarak ortaya çıktığı bildirilmektedir [2 ve 29]. Benzer şekilde, kayısı genotipleri arasında fenolojik evrelerde yaklaşık olarak 8 - 10 günlük farklılık görüldüğü Malatya'da yürütülen diğer bir çalışma da belirtilmektedir [10].

Kayısı çeşitleri arasında çiçeklenme zamanlarında gözlenen farklılıklar çeşitlerin çiçeklenmesi için gerekli sıcaklık toplamlarının farklı olması ile ilişkilidir [30]. Araştırmada incelenen kayısı çeşitlerinin çiçeklenme zamanı bakımından aynı yılda farklılıkların bulunmasıyla beraber yıllar arasında da varyasyon olduğu görülmektedir. Benzer durum, farklı kayısı çeşitleri için de tespit edilmiştir [31-329]. Nitekim, uzun yıllar boyunca yapılan gözlemlere bağlı olarak fenolojik safhaların, yıllara göre değişim gösterdiği ifade edilmektedir [33]. Bu durumun, özellikle erkenci çeşitlerde iklimin etkisine bağlı olarak yaygın şekilde görüldüğünden söz edilmektedir [34].

Kayısı çeşitlerinin yapraklanma başlangıcı ile ilgili veriler diğer çalışmalara benzerlik göstermektedir [35]. Yaprak dökümünün İzmir'de Kasım-Aralık, Malatya'da ise Kasım ayında olduğu belirlenmiştir. Lokasyonlar arasındaki bu farkl1lık, Malatya [13-12-36-37], Adana [24], Van [22] ve Erzincan [31] ekolojik koşullarında yetiştirilmekte olan kayısı çeşit ve tipleri için de ortaya konmuştur.

$\mathrm{Bu}$ araştırma sonucunda; Iğdır, Tokaloğlu, Precoce de Tyrinthe, Kabaaşı ve Hacıhaliloğlu kayısı çeşitlerinde iki farklı ekolojide 3 yıl süreyle yapılan fenolojik gözlemlerde çeşit, lokasyon ve yıllara bağlı bir değişim gözlenmiştir. Bu durumun, çeşitlerin genetik olarak soğuklama ihtiyaçlarının farklı olmasının yanı sıra, lokasyonların deniz seviyesinden yüksekliği ve yıllar arasındaki iklim farklılıkları nedeniyle ortaya çıkabildiği düşünülmektedir.

4.

\section{Teşekkür}

Çalışmanın yürütülmesi için maddi destek veren Ege Üniversitesi Bilimsel Araştırma Projeleri Birimi’ne

\section{Kaynakça}

[1] Asma B.M., "Kayısı Yetiştiriciliği”, İönü Üniversitesi, Malatya, 2000. 
[2] Özbek S., "Özel Meyvecilik, Kışın Yaprağını Döken Meyveler”, Çukurova Üniversitesi Ziraat Fakültesi Yayınları 128, Adana, 1978.

[3] Hedhly A., "Sensitivity of Flowering Plant Gametophytes to Temperature Fluctuations", Environmental and Experimental Botany, 74: 9 - 16pp, 2011.

[4] Güleryüz M., "Erzincan Ovasında İlkbahar Geç donlarına Mukavim ve Kaliteli Zerdali (Prunus armeniaca L.) Tiplerinin Seleksiyon Yoluyla Islahı Üzerinde Bir Araştırma”, Atatürk Üniv. Ziraat Fak., Tez, Erzurum, 95s, 1988.

[5] Çukadar K., Demirel H., Ünlü H.M., Aslay M., Bozbek Ö., "Kayısı Çeşit Seleksiyonu II", Türkiye V. Ulusal Bahçe Bitkileri Kongresi, 1: 391 - 395pp, 2007.

[6] Ağaoğlu Y.S., Çelik H., Çelik M., Fidan Y., Gülşen Y., Günay A., Halloran N., Köksal A.İ., Yanmaz Y., "Genel Bahçe Bitkileri”. Ankara Üniversitesi Ziraat Fakültesi Eğitim, Araştırma ve Geliştirme Vakfi Yayınlarl, Ankara, 4: 10-11s, 1997.

[7] Anonim, www.fsd.nl/downloadattachment/73471/guidelines-ges-fin_2.pdf, 2011.

[8] Crandall P.C., Daubeny H.A., "Small Fruit Crop Management”, Prentice Hall New Jersey, 157213pp, 1990.

[9] Vachun Z., "Phenophases of blossoming and picking maturity and their relationships in twenty apricot genotypes for a period of six years”, Scientia Horticulturae 30(2):43-50pp, 2003.

[10] Asma B.M., Kan T., Birhanlı O., "Characterization of promising apricot (Prunus armeniaca L.) genetic resources in Malatya, Turkey”. Genetic Resources and Crop Evolution, 54:205-212pp, 2007.

[11] Szalay L., Nemeth S., "Phenological Processes of Dormany in Apricot Genotypes in the Central Part of the Carpathian Basin”, Acta Hort., 862: 251 - 255pp, 2010.

[12] Acarsoy N., Evrenosoğlu Y., Kokargül R., Yılmaz K.U., Yiğit T., Gökalp K., Boztepe Ö., Gülcan R., Misırlı A., "Hacıhaliloğlu" F1 melez populasyonunda fenolojik ve bitkisel özelliklerin belirlenmesi, Türkiye VI. Ulusal Bahçe Bitkileri Kongresi, Şanlıurfa, 2011.

[13] Abacı Z.T., Asma B.M., "Bazı kayısı çeşitlerinin farklı ekolojik alanlardaki biyolojik özelliklerinin analizi”, Biyoloji Bilimleri Araştırma Dergisi, 3 (1):173-176s, 2010.

[14] Karlıdağ H., Bolat İ., "Yüksek Rakımda Yetiştirilen Kabaaşı ve Şekerpare Kayısı Çeşitlerinde Meyvelerin Fiziksel ve Kimyasal Özelliklerindeki Değişimin İncelenmesi”, Türkiye V. Ulusal Bahçe Bitkileri Kongresi, 1: 776 - 781s, 2007.

[15] Dejampour J., Zeinalabedini M., "Determination of Some Vegetative and Bloom Characteristics of Some Lokal Apricots in Azarbaijan (İran) Ecological Conditions”, Acta Hort., 717: 63 - 65pp, 2006.

[16] Yılmaz K.U., "Bazı Yerli Kayısı Genotiplerinin Fenolojik, Morfolojik ve Pomolojik Özellikleri ile Genetik İlişkilerinin ve Kendine Uyuşmazlık Durumlarının Moleküler Yöntemlerle Belirlenmesi Alatarım, Doktora tezi, Çukurova Üniversitesi Fen Bilimleri Enstitüsü Bahçe Bitkileri Anabilimdalı, 2008.

[17] Bostan, S.Z., "Darende zerdalilerinin (Prunus armeniaca L.) seleksiyon yoluyla 1slahı üzerine araştırmalar” Y.Y.Ü.Fen Bilimleri Enstitüsü Doktora Tezi, 1993.

[18] Apricot descriptor, International Union for the Protection of New Varieties of Plants, UPOV. 
[19] Ayanoğlu H., Sağlamer, M., “Akdeniz Bölgesi sahil şeridinde yetiştirilecek kayısı çeşitlerinin adaptasyonunda ilk sonuçlar” Derim Dergisi, (1), 3-15, 1986.

[20] Draganescu E., Cociu V., "The Modernizing of the Apricot Assortment of Cultivars in Banat Area of Romania”. XI. International Symposium on Apricot, Greece, Acta Hort. 488 (1):149151pp, 1997.

[21] Yılmaz K.U., "Bazı Yerli Kayısı Genotiplerinin Fenolojik, Morfolojik ve Pomolojik Özellikleri ile Genetik İlişkilerinin ve Kendine Uyuşmazlık Durumlarının Moleküler Yöntemlerle Belirlenmesi Alatarım, Doktora tezi, Çukurova Üniversitesi Fen Bilimleri Enstitüsü Bahçe Bitkileri Anabilimdalı, 2008.

[22] Asma B.M., Şen S.M., "Yerli ve Yabancı Kayısı Çeşitlerinin Van Ekolojik Şartlarındaki Fenolojik, Pomolojik ve Morfolojik Özellikleri”, Türkiye III. Ulusal Bahçe Bitkileri Kongresi, 760 - 763s, 1999.

[23] Seferoğlu H.G., Gülşen A.D., "Aydın Ekolojisinde Bazı Kayısı Çeşitlerinin Gelişme Performansları”, Türkiye IV. Ulusal Bahçe Bitkileri Kongresi, Antalya, 78 - 80s, 2003.

[24] Batmaz M.F., "Bazı Kayısı Genotiplerinin Adana Ekolojik Koşullarındaki Verim ve Kaliteleri”, Çukurova Üniversitesi Fen Bilimleri Enstitüsü, Yüksek Lisans Tezi, 2005.

[25] Kafkas E., Paydaş S., Burgut A., "Akdeniz Bölgesi Koşullarında Sofralık Bazı Kayısı Genotiplerinin Verim ve Kalite Özellikleri”, Türkiye V. Ulusal Bahçe Bitkileri Kongresi, 1: 235 - 240s, 2007.

[26] Paydaş S., Kaşka N., "Investigation on the Adaptation of Some Low- Chill apricot Cultivars to Adana (Turkey) Ecological Conditions”, Acta Hort., 384: 123 - 127pp, 1995.

[27] Paydaş S., Kaşka N., Küden A., "Yerli ve Yabancı Bazı Kayısı Çeşitlerinin Pozantı Koşullarındaki Performansları”, Türkiye II. Ulusal Bahçe Bitkileri Kongresi, Adana, 1: 169 173s, 1995.

[28] Önal K., Özakman S., Özkarakaş İ., "Ege Bölgesi Koşullarında Ümitvar Erkenci ve Kaliteli Kayısı (P. armeniaca) Çeşitlerinin Belirlenmesi”, Türkiye II. Ulusal Bahçe Bitkileri Kongresi, Adana, 164 - 168s, 1995.

[29] Karaçalı I., "Bahçe Ürünlerinin Muhafazası ve Pazarlanması”, Ege Ü. Basımevi, İzmir, 1990.

[30] Ageeva, N.G., "Winter hardiness of buds of new apricot varieties”, Plant Breeding Abst.,Vol, 69 (1), 627, 1987.

[31] Ertürk Y., Güleryüz M., "Bazı Yerli ve Yabancı Kayısı Çeşitlerinin Erzincan Koşullarındaki Vejetatif ve Generatif Gelişme Durumlarının Belirlenmesi”, Atatürk Üniv. Ziraat Fak. Derg. 39 (1), 9-14s, 2008.

[32] Mehlenbacher A., Cociu V., Hough L.F., "Apricots (Prunus). Genetic Resources of Temperate Fruit and Nut Crops”. ISHS, Acta Hort., I, 290: 63-107, 1998/99.

[33] Legave J.M., Clauzel G., "Long-Term Evolution of Flowering Time in Apricot Cultivars Grown in Southern France: Which Future Impacts of Global Warming?”, Acta Hort., 717: 47 - 50pp, 2006.

[34] Ruiz D., Egea J., "Analysis of the variability and correlations of floral biology factors affecting fruit set in apricot in a Mediterranean climate”, Scientia Horticulturae 115, 154-163pp, 2008 
Acarsoy Bilgin N., Misırlı A.

[35] Badenes M.L., Martinez-Calvo J., Llacer G., "Analysis of apricot germplasm from the European ecogeographical group”, Euphytica 102: 93-99pp, 1998. 